\title{
DIREITO INTERTEMPORAL DO CASAMENTO E A SÚMULA No 377 DO STF
}

\author{
Tereza Cristina Monteiro Mafra* \\ Rafael Baeta Mendonça**
}

RESUMO: O presente artigo tem como escopo analisar a dinâmica da intertemporalidade no Direito de Família, pela abordagem das constantes oscilações da jurisprudência, especialmente quanto à aplicação da Súmula $\mathrm{n}^{0} 377$ do STF. Pretende-se demonstrar, ainda, sob o marco teórico da teoria do direito transitório, de Paul Roubier, e metodologia dedutiva, que que a jurisprudência dos tribunais superiores não adota critérios claros para a aplicação do direito intertemporal no direito de família, sendo o maior exemplo a questão da súmula ${ }^{\circ} 377$ do STF, matéria sobre a qual há divergências e ausência de coerência na solução das controvérsias.

Palavras-chave: Intertemporalidade, Direito de família; Súmula $n^{0}$ 377, Segurança jurídica, Antinomia jurídica.

\section{INTERTEMPORAL LAW OF MARRIAGE AND THE PRECEDENT No 377 OF THE BRAZILIAN SUPREME COURT}

ABSTRACT: The purpose of this article is to analyze the dynamics of intertemporality in Family Law, by approaching the constant oscillations of jurisprudence, especially regarding the application of STF precedent $n^{\circ}$ 377. It is also intended to demonstrate, under the theoretical framework of Paul Roubier's theory of "transitional Law" and deductive methodology, that the jurisprudence of higher courts does not adopt clear criteria for the application of intertemporal Law in Family Law, the greatest example being the question of the STF precedent $n^{\circ} 377$, a matter on which there are divergences and lack of coherence in the solution of the controversies.

Keywords: intertemporality; family law; legal precedent $n^{\circ} 377$, legal certainty, Legal antinomy.

\section{INTRODUÇÃO}

Como qualquer manifestação cultural humana, as leis também são transitórias. Lembra Batalha que "tudo o que existe desliza num perpétuo fluxo, na corrente da vida, ao perpassar dos tempos” (BATALHA, 1980, p. 47).

\footnotetext{
* Doutora em Direito na Faculdade de Direito da UFMG. Diretora do Programa de Pós-Graduação em Direito da Faculdade de Direito Milton Campos (FDMC). Advogada. E-mail: tereza.c.mafra@terra.com.br. Endereço Profissional: Alameda Oscar Niemeyer, $n^{\circ}$ 500, Sala 707, Vale do Sereno, Nova Lima/MG.

** Mestrando na Faculdade de Direito Milton Campos (FDMC). Pós-graduado em Direito de Família e Sucessões pela Faculdade Arnaldo Janssen. Advogado. E-mail: rafaelbaeta@hotmail.com. Endereço Profissional: Alameda Oscar Niemeyer, $n^{\circ}$ 500, Sala 707, Vale do Sereno, Nova Lima/MG.
} 
Especialmente quanto ao direito de família, Menezes Direito afirma que "não há instituição, por mais que se queira conservadora, que tenha exigido dos legisladores um tratamento de constante trânsito para permitir que sejam atualizados os seus institutos, a começar do próprio conceito de entidade familiar” (DIREITO, 2006, p. 45).

Por outro lado, os valores como bem comum, interesse social e público exigem a aplicação imediata de novos cânones. Eis o problema, a dinâmica da intertemporalidade. Diante de um possível conflito entre duas normas positivas consecutivas sobre o mesmo assunto, o direito intertemporal tem por objetivo determinar os limites do domínio de cada uma, indicando ao juiz qual a norma jurídica em que deve basear a sua decisão. (MAXIMILIANO, 1955, p. 07).

Aqui se propõe analisar as constantes oscilações da jurisprudência, especialmente quanto à aplicação da Súmula no 377 do Supremo Tribunal Federal, demonstrando, ainda, que a sua aplicação aos casados sob a égide do Código Civil de 2002, como vem procedendo o Superior Tribunal de Justiça, é incoerente com as normas do direito intertemporal.

Após a introdução, nosso artigo, em seu capítulo dois, expõe as noções gerais do direito intertemporal, com ênfase nos princípios fundamentais do ordenamento jurídico brasileiro quanto à dinâmica da intertemporalidade. Apresenta-se a teoria do direito transitório, de Paul Roubier, e justifica-se a sua escolha como marco teórico; dentro da metodologia dedutiva adotada para enfrentar o problema objetivo do nosso artigo, qual seja: a aplicação da súmula nº 377 do STF aos casados sob a vigência do CC/2002 observa as normas de direito intertemporal do ordenamento jurídico brasileiro?

O capítulo três faz uma breve apresentação do fenômeno da intertemporalidade aplicada ao casamento. Por fim, no capítulo quatro são examinadas as principais questões de direito intertemporal no direito de família, especialmente no que tange ao âmbito de aplicação da súmula $\mathrm{n}^{\circ} 377$ do STF pelos tribunais superiores.

Por fim, o artigo concluirá que a jurisprudência dos tribunais superiores não adota critérios claros para a aplicação do direito intertemporal no direito de família, sendo o maior exemplo a questão da súmula $n^{\circ} 377$ do STF, matéria sobre a qual há divergências e ausência de coerência.

\section{NOÇÕES GERAIS DO DIREITO INTERTEMPORAL}

\section{Revista de Direito de Família e Sucessão | e-ISSN: 2526-0227 | Maranhão | v. 3 | n. 2 | p.}


Uma das principais manifestações do tempo no âmbito dos direitos subjetivos é a garantia que deve ser atribuída aos seus titulares, significando segurança jurídica, continuidade e paz social, mediante a proteção dos direitos adquiridos. Quando leis se sucedem, as mais variadas relações jurídicas se estabelecem, prolongando-se sob o império da nova lei e fazendo surgir situações transitórias denominadas conflitos de leis no tempo.

Trata-se de saber em que medida a lei antiga perdurará, incidindo sobre relações jurídicas nascidas à sua luz, apesar da entrada em vigor da nova lei. Pela sobrevida da lei velha pugnam os valores de confiança, continuidade, segurança jurídica e paz social, que deveriam garantir direitos validamente adquiridos e consolidados sob essa lei antiga.

Diversamente do direito internacional, que trata do conflito de leis no espaço, o direito intertemporal disciplina “as relações jurídicas surgidas ou reinantes no tempo intermédio entre o domínio de uma norma e o império da subsequente”. A despeito de suas particularidades, tanto o direito internacional quanto o direito intertemporal têm o mesmo objetivo geral, qual seja, resolver os conflitos de leis, apontando a lei competente para regulamentar uma situação jurídica específica (MAXIMILIANO, 1955, p. 08.)

No século XX, a mais famosa tese a respeito é a teoria do direito transitório, de Paul Roubier, segundo a qual a criação de uma situação jurídica, inclusive a aquisição de um direito, assim como os efeitos já produzidos, são e permanecem sendo regidos pela lei em vigor no momento em que se realizou o vínculo jurídico ou em que se adquiriu o direito, embora os efeitos sucessivos da relação jurídica previamente formada, assim como a respectiva causa de extinção, dando-se sob a nova lei, a ela se submetem (ROUBIER, 2008).

Deve-se ao referido autor a distinção entre efeito retroativo e efeito imediato da lei nova: o efeito retroativo é a aplicação da lei no passado e, por sua vez, o efeito imediato, a aplicação no presente.

São três as relações jurídicas possíveis entre a lei nova e a lei antiga: a) retroatividade da lei nova, se sua aplicação remonta ao passado; b) efeito imediato da lei nova, quando ela se aplica ao presente; c) sobrevivência da lei antiga, quanto às situações ocorridas já na vigência da lei nova.

A lei nova alcança imediatamente a situação jurídica em curso, mas não pode modificar, sob pena de atuar retroativamente, as consequências já produzidas. Entretanto, a regra 
se inverte em sede contratual: os efeitos dos contratos continuam sendo submetidos às leis em vigor quando concluída a avença.

Em outras palavras, se a lei nova atinge situações jurídicas constituídas ou extintas na vigência da lei antiga (facta praeterita), ou se afeta os efeitos dessas situações, produzidos na vigência da lei antiga, então a lei nova será retroativa; mas, se a lei nova incide sobre as situações em curso (facta pendentia), ou seja, sobre os efeitos futuros de situações jurídicas constituídas na vigência da lei antiga, então a lei nova não terá efeito retroativo, mas sim efeito imediato, ressalvadas as hipóteses em que o legislador reconhece a sobrevivência da lei antiga para reger os efeitos futuros das situações jurídicas constituídas na vigência daquela lei (ROUBIER, 1929, p. 371).

Como exemplo de efeito imediato (e não retroativo) de uma lei nova sobre situações em curso de constituição, pode-se afirmar que a lei nova não pode modificar as condições de validade de forma de um testamento anteriormente feito, sem retroagir, já que as leis aplicáveis às formalidades extrínsecas são sempre as da época da elaboração do testamento, sendo que não se pode exigir do testador que realize as adequações do seu testamento às alterações da lei em vigor. Ao contrário, a lei nova pode modificar as condições de validade das disposições de fundo ou intrínsecas dos testamentos, eis que tais disposições somente têm eficácia no momento do falecimento do testador.

Rege-se a forma de todo ato jurídico pela lei do tempo em que ele se realiza, ainda que uma lei posterior imponha o contrário, sob pena de nulidade, ou dispense ou atenue o exigido pela lei anterior. Tanto a validade intrínseca quanto a extrínseca obedecem ao brocardo tempus regit actum (MAXIMILIANO, 1955, p. 35).

No momento em que a norma válida e eficaz incide sobre os fatos previstos em seu suporte fático, verificam-se os seus efeitos. Nesse sentido, já se sustentou que "não apenas se pode falar em eficácia da norma em vigor, pois não é estranha ao Direito a possibilidade de a norma revogada produzir efeitos” (MAFRA, 2008, p. 107).

A norma revogada por outra, expressa ou tacitamente, perde a possibilidade de produzir efeitos sobre fatos que ocorreram a partir da revogação, mas as situações configuradas sob sua vigência permanecem sofrendo sua incidência, sob pena de lesão à segurança jurídica.

\section{Revista de Direito de Família e Sucessão | e-ISSN: 2526-0227 | Maranhão | v. 3 | n. 2 | p.}


Para Roubier, o efeito imediato da lei dever ser considerado como a regra. Mas, pode acorrer a chamada "sobrevivência da lei antiga" (survie de la loi ancienne) quando a lei nova deixa a lei antiga aplicar-se a todos os efeitos jurídicos futuros de fatos anteriores à sua promulgação. Por exemplo, a lei nova declara que a prescrição, iniciada na vigência da lei antiga, continua a fluir de acordo com o prazo previsto pela lei antiga, embora diverso o prazo na nova lei (ROUBIER, 1929, p. 09-10).

A Constituição vigente dispõe em seu art. 5 XXXVI: “A lei não prejudicará o direito adquirido, o ato jurídico perfeito e a coisa julgada”. Em regra, prevalece a irretroatividade da lei nova, se a lei anterior teve plena incidência sobre a relação jurídica de que se trata.

Delgado adverte que, mesmo no Direito brasileiro, em que a questão mereceu tratamento constitucional, o princípio da irretroatividade não é regra absoluta, de modo que a lei nova que traga em seu bojo alguma carga de retroatividade não será necessariamente inconstitucional (DELGADO, 2004, p. 14-15).

No sistema ordinário, a matéria concernente ao Direito Intertemporal funda-se principalmente no art. $6^{\circ}$ da Lei de Introdução de 1942, com as modificações da Lei n. 3.238, de 1957.

A Lei n. 3.238, de 1957, uniu o art. $3^{\circ}$ da Lei de Introdução de 1916, e o art. $6^{\circ}$ originário da Lei de 1942, assentado sobre a teoria de Roubier, na parte referente ao efeito imediato das leis.

Portanto, no Brasil, o efeito imediato da lei constitui a regra: a norma positiva aplicase às situações em curso, a partir de sua entrada em vigor.

Tendo em vista os avanços na legislação e na doutrina brasileira pode-se afirmar que, de acordo com a regra do efeito imediato, a nova lei não atinge os fatos anteriores, nem os efeitos anteriores desses fatos.

Por outro lado, atinge os facta futura, assim como os efeitos futuros dos facta praeterita, sendo certo que o limite do efeito imediato é o direito adquirido, o ato jurídico perfeito e a coisa julgada. ${ }^{1}$

\footnotetext{
${ }^{1}$ Quanto ao direito adquirido e o ciclo de formação, o SUPREMO TRIBUNAL FEDERAL decidiu que "a questão pertinente ao reconhecimento, ou não, da consolidação de situações jurídicas definitivas há de ser examinada em face dos ciclos de formação a que esteja eventualmente sujeito o processo de aquisição de determinado direito. Isso significa que a superveniência de ato legislativo, em tempo oportuno - vale dizer,
} 
Em outros termos, no direito intertemporal brasileiro destacam-se dois princípios fundamentais: a) o do efeito imediato da lei, pelo qual a lei nova se aplica a todos os fatos que ocorrerem durante a sua vigência; e b) o da irretroatividade, pelo qual os fatos verificados sob o império da lei antiga continuam regidos por ela, respeitando-se o ato jurídico perfeito, o direito adquirido e a coisa julgada, tudo isso em favor da segurança jurídica. Esses dois princípios correspondem a duas concepções teóricas fundamentais: a objetiva de Roubier, que distingue o efeito retroativo do efeito imediato da lei, e a subjetiva, de Gabba, que estabelece, como limite à vigência da lei nova, o direito adquirido.

Por efeito imediato da lei se deve entender aquele que atinge fatos e situações no exato momento temporal em que esta entra em vigor, não importando juridicamente se tais fatos ou situações remontam, na sua origem, a uma lei por esta nova substituída. As controvérsias, no tocante à eficácia imediata da lei nova, são suscitadas pelos facta pendentia (CARDOZO, 1995, p. 281).

Isso porque os atos jurídicos perfeitos, representando fatos consumados ao tempo em que determinada norma era vigente, asseguram aos titulares do ato ou negócio aperfeiçoado, a proteção do direito adquirido, incorporado definitivamente ao seu patrimônio e à sua personalidade. Ou, como explica Rubens Limongi França, o direito adquirido "é o limite da atuação da regra do efeito imediato”. O problema se situa na identificação de quais seriam os limites do direito adquirido, especialmente em relação aos facta pendentia (FRANÇA, 1982, p. 210).

Os facta pendentia, que são os nascidos sob o domínio da lei anterior, mas correspondem a situações continuativas, que se prolongam por tempo indeterminado, frequentemente são atingidos, em seu curso, por uma lei nova.

Logo, a retroatividade de um diploma legal refere-se sempre à sua ação pretérita. Ou seja, à sua ação projetada para período anterior ao da sua vigência, de forma a atingir ou modificar realidades fáticas jurídicas já verificadas. Trata-se de atribuir a ação de uma lei ao

enquanto ainda não concluído o ciclo de formação e constituição do direito vindicado - constitui fator capaz de impedir que se complete, validamente, o próprio processo de aquisição do direito (RTJ 134/1112 - RTJ 153/82 RTJ 155/621, v. g.), inviabilizando, desse modo, ante a existência de mera "spes juris”, a possibilidade de útil invocação da cláusula pertinente ao direito adquirido.” (Recurso Extraordinário n. 196.140-6/PA, Primeira Turma, Relator Min. Celson de Mello, data do julgamento 25.02.1997, Ementário n. 2244-4, D. J. 25.08.2006). 
passado. Na definição de retroatividade, pois, não se pode vislumbrar a atuação de uma norma sobre o presente ou o futuro (CARDOZO, 1995, p. 257).

Ferraz Jr., ao tratar da irretroatividade das leis, faz a distinção entre incidência de normas de competência e normas de conduta: normas de competência qualificam certos atos sob certas condições como de produzir certos efeitos, já as normas de conduta estabelecem linhas de ação, às quais imputam consequências (FERRAZ JÚNIOR, 1994, p. 250).

Se a lei antiga contém normas de competência que estabelecem as condições em que alguém é considerado titular de direitos subjetivos, preenchidas essas condições diz-se que o direito está adquirido, isto é, ocorreu a incidência no sentido de que o adquirente está apto a exercê-lo.

Alerta Ferraz Jr. que o princípio do direito adquirido não protege, porém, o sujeito contra uma lei posterior no que diz respeito à incidência de novas normas de conduta. Assim, protegida a aquisição de um status de proprietário, por exemplo, nada obsta que o exercício de certos atos correspondentes ao direito de propriedade venha a ser atingido por lei posterior que proíba alguma conduta. Daí a importância do princípio do ato jurídico perfeito, isto é, o preceito segundo o qual o ato exercitado e consumado sob a norma de conduta da lei antiga não pode ser atingido pela lei posterior (FRANÇA, 1994, p. 250-251).

Note-se que são situações distintas e reguladas por normas distintas: o princípio do direito adquirido protege a situação de titular já adquirida, e, por sua vez, o princípio do ato jurídico perfeito protege o titular que exerceu seu direito conforme normas de conduta vigentes à época.

Por fim, é bastante controversa na doutrina a discussão quanto à possibilidade de a lei nova, de ordem pública, atingir os efeitos futuros de situações jurídicas consolidadas sob a vigência da lei antiga.

Havendo conflito entre o direito adquirido e a ordem pública, diante dos interesses desta, entende a doutrina que aquele, geralmente, deve ceder. Contudo, em determinados casos, o critério para se saber quando uma lei de ordem pública não deve atingir o direito adquirido, quer retroativa, quer imediatamente, é o de que "o fundamento da Ordem Pública, para desconhecer o Direito Adquirido, não pode ir a ponto de atingir os casos em que esse desconhecimento geraria o desequilíbrio social e jurídico.” (FRANÇA, 1994, p. 311). 
Examinando-se a jurisprudência do Supremo Tribunal Federal verifica-se entendimento consolidado no sentido de que o art. $5^{\circ}$, XXXVI, da Constituição se aplica a toda e qualquer lei infraconstitucional, seja de direito público ou privado, de caráter imperativo ou dispositivo, de modo que não há que se falar em aplicação de norma de ordem pública a fatos consumados (ou a seus efeitos) antes de sua entrada em vigor. ${ }^{2}$

Cabe, então, analisar a questão da ordem pública conjugal, tendo em vista, de um lado, as feições do casamento no século XXI, e, de outro lado, em um contexto de contratualização e liberalização constante das relações conjugais, qual a dimensão e qual a intensidade da interferência estatal.

\section{SÍNTESE DO DIREITO TRANSITÓRIO NO CASAMENTO}

A família é um fenômeno social, antecedente ao Estado, ao Direito e à Igreja. Sofre as influências do tempo, mas a ele resiste, amoldando-se, de sorte que seus modelos sejam finalizados para a promoção da dignidade e da felicidade daqueles que a ela pertencem.

Os costumes sociais dessas famílias ou nessas famílias abrangem diversas manifestações e contêm especificidades próprias, conforme o local e o tempo investigados.

\footnotetext{
2 "Sendo constitucional o princípio de que a lei não pode prejudicar o ato jurídico perfeito, ele se aplica também às leis de ordem pública.” (SUPREMO TRIBUNAL FEDERAL. Recurso Extraordinário n. 205.999/SP, Rel. Ministro MOREIRA ALVES, data de julgamento 16.11.1999, D. J. 03.03.2000, p. 89, Ementário n. 1.981-05, p. 991).

"Os contratos submetem-se, quanto ao seu estatuto de regência, ao ordenamento normativo vigente à época de sua celebração. Mesmo os efeitos futuros oriundos de contratos anteriormente celebrados não se expõem ao domínio normativo de leis supervenientes. As consequências jurídicas que emergem de um ajuste negocial válido são regidas pela legislação que se achava em vigor no momento da celebração do contrato (tempus regit actum): exigência imposta pelo princípio da segurança jurídica. Os contratos, que se qualificam como atos jurídicos perfeitos (RT 547/215), acham-se protegidos, inclusive, quanto aos efeitos futuros deles decorrentes pela norma de salvaguarda constante do art. $5^{\circ}$, XXXVI, da Constituição da República, cuja autoridade sempre prevalece, considerada a supremacia que lhe é inerente, mesmo que se trate de leis de ordem pública." (SUPREMO TRIBUNAL FEDERAL. Recurso Extraordinário em Agravo Regimental n. 393.021/SP, Rel. Ministro CELSO DE MELLO, data de julgamento 25.11.2003, D. J. 12.08.2005, p. 18, Ementário n. 1.981-05, p. 991).

"Lei n. 8.030/90. Efeitos retroativos sobre contratos anteriores a sua edição. Art 5, XXXVI, da CF/88. Ofensa Direta. 1. O controle de constitucionalidade exercido em hipótese de ofensa ao princípio da irretroatividade das leis (art. $5^{\circ}$, XXXVI, da CF/88) pressupõe a interpretação da lei ordinária, cuja validade se pretende questionar, não havendo que se falar em ofensa indireta. 2 . O despacho agravado fundou-se em jurisprudência consolidada deste Supremo Tribunal, no sentido de que, no nosso ordenamento jurídico, a legislação infraconstitucional, ainda quando de ordem pública, não pode retroagir para alcançar ato jurídico perfeito. 3. Agravo regimental a que se nega provimento.” (SUPREMO TRIBUNAL FEDERAL. Recurso Extraordinário em Agravo Regimental n. 263.161/BA, Rel. Ministra ELLEN GRACIE, data de julgamento 08.10.2002, D. J. 06.12.2002, p. 65, Ementário n. 2.094-02, p. 391).
} 
O direito de família é profícuo em facta pendentia, tanto pela proliferação legislativa, quanto pela natureza de duração indefinida de suas múltiplas relações jurídicas, que não se realizam e concluem em um só momento, mas se desenvolvem no tempo, representando campo fértil para tal debate.

Além de se prolongarem no tempo, as relações de direito de família produzem tanto efeitos pessoais, quanto patrimoniais, envolvem direitos indisponíveis e outros disponíveis, ora sendo predominante matéria de ordem pública, ora prevalecendo a autonomia privada.

A expressão ordem pública é tão difusa que, segundo Maularie, ninguém jamais foi capaz de defini-la com precisão, todos tateando no escuro (MALAURIE, 1951, p. 3). Para Seabra Fagundes, ordem pública, sob o prisma jurídico, manifesta-se sob dupla conotação:

Ora aparece como designativa de parâmetros basilares de comportamento social (no mais amplo sentido, isto é, com relação aos costumes morais, à estrutura e vida de família, à economia geral, etc), ora diz com o clima de equilíbrio e paz indispensável à convivência coletiva do dia-a-dia (CRETELLA JÚNIOR. Apud PIRES, 2005, p. 354).

No direito de família, a ordem pública age de uma só vez sobre a estrutura do casamento e sobre o comportamento das pessoas. A igualdade se impõe no âmbito dos direitos pessoais e patrimoniais, devendo-se também mencionar seu prolongamento na esfera parental, com o desaparecimento do pátrio poder dando lugar à imposição legal de tratamento igualitário entre os pais.

Conquanto não se admita a eventual retroatividade das leis de ordem pública, deve-se destacar que, no centro da ordem pública no direito de família contemporâneo se encontram os direitos fundamentais da pessoa (NIBOYET, 2008; 2001).

Diante da evolução do direito de família não é mais possível apenas aderir à doutrina de direito intertemporal sobre o casamento, porque alguns autores brasileiros (BATALHA, 1980, p. 342-343; ESPÍNOLA, 1999, v. 1, p. 310-312) se limitaram a incorporar a tese de Paul Roubier, fundada em Hauriou, que o qualifica como instituição (ROUBIER, 2008, p. 423-431), e outros autores se limitaram a reproduzir os mesmos comentários de Roubier sobre os efeitos do casamento, simplesmente suprimindo a explicação prévia sobre a natureza do instituto (DINIZ, 2005, p. 205; MAXIMILIANO, 1955, p. 80-92; OLIVEIRA, 1998, v. 1, p. 297-299). 
Serão examinadas, a seguir, as principais questões de direito intertemporal no direito de família, após breve análise de seus mais importantes institutos, à luz do critério proposto, destacando-se que o Código Civil de 2002, nas Disposições finais e transitórias, regulou expressamente alguns aspectos de direito intertemporal, sendo especificamente relativo ao direito de família o art. $2039^{3}$.

\section{DIREITO PATRIMONIAL INTERTEMPORAL E A SÚMULA No 377 DO STF}

O direito patrimonial do casamento, previsto no Código Civil de 2002, embora tenha trazido algumas importantes modificações ${ }^{4}$, reflete uma regulamentação muito semelhante à contida no Código revogado, exceto quanto às necessárias adaptações, constitucionalmente impostas, que se refletiram no chamado regime primário ou estatuto imperativo de base, que contém regras gerais, inderrogáveis pela vontade dos cônjuges, relativas a certos efeitos pessoais e patrimoniais do casamento ${ }^{5}$.

Quanto aos aspectos de direito intertemporal no direito patrimonial do casamento, prevê o art. 2.039 do CC/2002 que o regime de bens nos casamentos celebrados na vigência do Código Civil anterior é o por ele estabelecido.

De acordo com Carlos Maximiliano

o Direito imperante na data do matrimônio fixa, de modo invariável para o futuro, as relações patrimoniais entre os cônjuges, quer quanto às disposições imperativas, quer quanto às supletivas da vontade das partes: por exemplo, o regime dos bens, quer advenha de contrato antenupcial, quer da própria lei; assim como a proibição de doações ou dádivas entre esposos. Portanto a lei vigente ao celebrarem-se as núpcias regula os direitos dos consortes sobre os bens comuns e sobre os pessoais separados; obrigações por dívidas anteriores

\footnotetext{
${ }^{3}$ Art. 2.039. O regime de bens nos casamentos celebrados na vigência do Código Civil anterior, Lei 3.071, de $1^{\text {o }}$ de janeiro de 1916, é o por ele estabelecido.

${ }^{4}$ Podem ser mencionadas algumas das mais importantes, tais como: a mutabilidade do regime de bens (art. 1.639, § $2^{\circ}$ ); a dispensa da outorga conjugal no regime de separação absoluta (art. 1.647); a exigência de outorga conjugal no aval (art. 1.647, III); o regime de participação final nos aquestos (arts. 1.672 a 1.686), que substituiu o regime dotal; a possibilidade de ser convencionada a livre disposição dos imóveis, desde que particulares, no regime de participação final nos aquestos (art. 1.656); a incomunicabilidade dos proventos do trabalho pessoal de cada cônjuge (art. 1.659, VI); a não recepção do princípio de comunicação dos aquestos (art. 259, CC/1916). ${ }^{5}$ Várias dessas normas foram abolidas em razão do princípio da igualdade, como aquelas que, no Código de 1916, atribuíam ao marido a chefia da sociedade conjugal (art. 233), incumbiam-lhe de prover a manutenção da família (art. 233, IV) e previam ser o regime de bens imutável (art. 230).
} 
ao casamento ou com o mesmo concomitantes (MAXIMILIANO, 1955, p. 86).

Diante disso, as relações conjugais de natureza patrimonial devem ser regidas pela lei antiga. Ou seja, mesmo que a lei nova estabeleça novos e diversos regimes supletivo legal e obrigatório, os casamentos celebrados sob a vigência do Código Civil de 1916 continuarão com os regimes de bens por ele regulados.

No Código Civil de 1916, havia uma regra de interpretação dos pactos antenupciais, que dispunha: "Art. 259. Embora o regime não seja o da comunhão de bens, prevalecerão, no silêncio do contrato, os princípios dela, quanto à comunicação dos adquiridos na constância do casamento".

Uma das consequências da aplicação do art. 259, do Código Civil de 1916, que, vale repetir, tem incidência quanto aos casamentos celebrados sob a vigência daquela legislação (Código Civil de 2002, art. 2.039), era admitir-se dois possíveis regimes de separação de bens convencionais $^{6}$ : a separação total ou absoluta e a separação parcial ou relativa, como se extrai de voto proferido pelo Ministro Moreira Alves:

Por outro lado, da simples leitura do art. 259, verifica-se que o regime da separação convencional se subdivide em regime da separação convencional absoluta e regime de separação convencional relativa. Absoluta, quando constar do pacto antenupcial que os nubentes estipulam a separação de todos os bens passados, presentes e futuros; relativa, quando do pacto não constar essa cláusula de exclusão de bens futuros ou adquiridos posteriormente ao casamento ${ }^{7}$.

A completa segregação patrimonial deveria ser minuciosa e expressa (separação convencional absoluta). Se o pacto indicar, inequivocamente, a incomunicabilidade de todos os bens, presentes e futuros, assim como dos respectivos acessórios (frutos, benfeitorias, rendimentos, etc), afastando todas as hipóteses de comunicação previstas na comunhão de bens,

\footnotetext{
6 Convencionais porque estabelecidos via pacto antenupcial, no exercício da liberdade de pactuar dos noivos (art. 256, Código Civil de 1916).

${ }^{7}$ Casamento. Regime de absoluta separação de bens, estipulado através de pacto antenupcial. Desquite. A determinação do acórdão recorrido de proceder-se a partilha dos bens adquiridos na constancia da sociedade conjugal importa em negação de vigencia do disposto no art. 256 do código civil. Recurso Extraordinário conhecido e provido. (SUPREMO TRIBUNAL FEDERAL. Segunda Turma, Relator Min. Thompson Flores, Recurso Extraordinário no 80496/SP, j. 29.11.1977. Disponível em: www.stf.jus.br. Acesso em: 31.10.2017).
} 
prevalece a separação total, inviabilizando-se, como firmou entendimento o Superior Tribunal de Justiça, o reconhecimento de sociedade de fato entre os cônjuges ${ }^{8}$.

Não havendo a explícita exclusão dos aquestos ${ }^{9}$, presume-se sua comunicabilidade, regra extensiva aos acessórios (separação convencional relativa). Isso porque, no silêncio do contrato, quer dizer, na omissão do pacto antenupcial, quanto ao destino dos bens adquiridos onerosamente durante o casamento, prevaleceriam os princípios da comunhão (parcial), consoante posicionamento adotado pelo Supremo Tribunal Federal ${ }^{10}$.

Outra modalidade de regime separatista, previsto no Código de 1916, era consignado no art. 258, parágrafo único. Nos casos ali consignados, suprimia-se dos nubentes a liberdade de pactuar, impondo-se-lhes um regime, denominado separação obrigatória de bens, configurando

8 CASAMENTO. PACTO ANTENUPCIAL. SEPARAÇÃO DE BENS. SOCIEDADE DE FATO. RECONHECIMENTO. IMPOSSIBILIDADE. DIVISÃO DOS AQÜESTOS. - A cláusula do pacto antenupcial que exclui a comunicação dos aqüestos impede o reconhecimento de uma sociedade de fato entre marido e mulher para o efeito de dividir os bens adquiridos depois do casamento. Precedentes. (SUPERIOR TRIBUNAL DE JUSTIÇA. Terceira Turma, Relator Min. Ministro Humberto Gomes de Barros, Recurso Especial nº 404088/RS, j. 17.04.2007. Disponível em: www.stj.jus.br. Acesso em: 31.10.2017).

CIVIL. PACTO ANTENUPCIAL EXCLUDENTE DA COMUNICAÇÃO DOS AQÜESTOS. A cláusula do pacto antenupcial que exclui a comunicação dos aqüestos impede o reconhecimento de uma sociedade de fato entre marido e mulher para o efeito de dividir os bens adquiridos depois do casamento. Recurso especial não conhecido. (SUPERIOR TRIBUNAL DE JUSTIÇA. Terceira Turma, Relator Min. Ministro Ari Pargendler, Recurso Especial no 141062/PA, j. 05.04.2001. Disponível em: www.stj.jus.br. Acesso em: 31.10.2017).

CASAMENTO. REGIME DA COMPLETA SEPARAÇÃO DE BENS. PACTO ANTENUPCIAL. COMUNICAÇÃO DOS AQÜESTOS. - Pretensão de interpretar-se o alcance de cláusula inserta no pacto antenupcial. Inadmissibilidade no apelo especial (súmula n ${ }^{\circ}$ 05-STJ). - Estipulado expressamente, no contrato antenupcial, a separação absoluta, não se comunicam os bens adquiridos depois do casamento. A separação pura é incompatível com a superveniência de uma sociedade de fato entre marido e mulher dentro do lar. Precedentes (REsp's nos 2.541-0/SP e 15.636-RJ) - Incidência, ademais, do verbete sumular $n^{\circ}$ 07-STJ. Recurso especial não conhecido. (SUPERIOR TRIBUNAL DE JUSTIÇA. Quarta Turma, Relator Min. Ministro Barros Monteiro, Recurso Especial no 83750/RS, j. 19.08.1999. Disponível em: www.stj.jus.br. Acesso em: 31.10.2017).

${ }^{9}$ Na enumeração legal (art. 271, do Código Civil de 1916), aquestos são os bens adquiridos na constância do casamento, por título oneroso, ainda que só em nome de um dos cônjuges; os adquiridos por fato eventual; por doação, herança ou legado em favor de ambos os cônjuges; as benfeitorias em bens particulares de cada cônjuge; os frutos dos bens comuns ou dos particulares de cada cônjuge ou de ambos; os frutos civis do trabalho ou indústria de cada cônjuge ou de ambos. Ou seja, os bens comuns na comunhão parcial.

${ }^{10}$ Afirma-se que a interpretação do art. 259, do Código Civil de 1916, na parte referente aos "princípios da comunhão" tratar-se da aplicação das regras da comunhão parcial com fundamento na jurisprudência do STF:

"Comunhão dos aquestos, em regime de separação, consagrada pela jurisprudência. Conhecimento e provimento do recurso, em parte.” (SUPREMO TRIBUNAL FEDERAL, Segunda Turma, Relator Min. Antônio Villas Boas, Recurso Extraordinário $\mathrm{n}^{\circ}$ 44.807, j. 05.08.1960. Disponível em <http://www.stf.jus.br>. Acesso em 31.10.2017).

"Ainda que de separação convencional o regime, são comuns, se nada se estipulou em contrário, os bens adquiridos (art. 259, CC).” (SUPREMO TRIBUNAL FEDERAL, Primeira Turma, Relator Min. Mário Guimarães, Recurso Extraordinário n 27.043, j. 04.11.1954. Disponível em <http://www.stf.jus.br>. Acesso em 31.10.2017).

Revista de Direito de Família e Sucessão | e-ISSN: 2526-0227 | Maranhão | v. 3 | n. 2 | p. 36 - 55 | Jul/Dez. 2017. 
restrição à autonomia privada dos noivos, já que a regra geral, prevista no art. 256 do CC/1916, autorizava-os a estipular, quanto aos seus bens, o que lhes aprouvesse.

Alude-se à separação obrigatória, porque começaram a surgir controvérsias sobre a incidência do art. 259, do Código Civil de 1916, que se referia, especificamente, às hipóteses de silêncio do contrato, a esse regime. Ora, na separação obrigatória, não há que se falar em contrato. O regime é imposto pela lei. Pontes de Miranda, a respeito, assevera

No acórdão da Primeira Turma do Supremo Tribunal Federal, de 7 de outubro de 1947 (RF 126/430), parece que se reputou ser apenas concernente aos bens trazidos pelos cônjuges o regime da separação legal, o que é absurdo, pois o art. 259 é regra jurídica dispositiva que só se pode invocar quando haja autoregramento da vontade (= autonomia da vontade), e não onde não no há (PONTES DE MIRANDA, 2001, v. 2, p. 213).

No Código de 1916, eram quatro hipóteses: I - das pessoas que celebraram casamento com infração do estatuído no art. 183, XI a XVI (art. 216); II - do maior de 60 (sessenta) e da maior de 50 (cinqüenta) anos; III - do órfão de pai e mãe, ou do menor, nos termos dos arts. 394 e 395, embora case, no termos do art. 183, XI, com o consentimento do tutor; IV - de todos os que dependerem, para casar, de autorização judicial (arts. 183, XI, 384, III, 426, I, e 453).

Os casamentos celebrados com inobservância do disposto no art. 183, XI a XVI, do Código Civil de 1916, correspondiam aos seguintes casos: XI - Os sujeitos ao pátrio poder, tutela, ou curatela, enquanto não obtiverem, ou lhes não for suprido o consentimento do pai, tutor, ou curador (art. 211); XII - As mulheres menores de dezesseis anos e os homens menores de dezoito; XIII - O viúvo ou a viúva que tiver filho do cônjuge falecido, enquanto não fizer inventário dos bens do casal (art. 226); XIV - A mulher viúva ou separada do marido por nulidade ou anulação do casamento, até dez meses depois da viuvez ou da separação judicial dos corpos, salvo se, antes de terminado o referido prazo, der à luz algum filho; XIV - A viuva, ou a mulher cujo casamento se desfez por ser nullo ou ter sido annullado, até dez mezes depois do começo da viuvez, ou da dissolução da sociedade conjugal, salvo se antes de findo esse prazo dér à luz algum filho; XV - O tutor ou curador e os seus descendentes, ascendentes, irmãos, cunhados ou sobrinhos, com a pessoa tutelada ou curatelada, enquanto não cessar a tutela ou curatela, e não estiverem saldadas as respectivas contas, salvo permissão paterna ou materna manifestada em escrito autêntico ou em testamento; XVI - O juiz, ou escrivão e seus 
descendentes, ascendentes, irmãos, cunhados ou sobrinhos, com órfão ou viúva, da circunscrição territorial onde um ou outro tiver exercício, salvo licença especial da autoridade judiciária superior.

Os sujeitos ao pátrio poder (hoje, poder familiar), tutela ou curatela, caso não obtivessem consentimento dos respectivos representantes legais, bem como os homens menores de 18 anos e as mulheres menores de 16 anos (sem idade núbil) contraíam casamentos anuláveis e, por consequência legal, sob o regime da separação obrigatória. Lembrando que o regime supletivo legal do Código Civil de 1916, até o advento da Lei do Divórcio (de 1977), era a comunhão universal, buscava-se proteger os incapazes.

Quanto ao viúvo ou à viúva que tiver filho do cônjuge falecido, enquanto não fizer inventário dos bens do casal, o objetivo do legislador era o de evitar a confusão de patrimônios. O inventário e a partilha permitem distinguir a meação do cônjuge sobrevivente e a herança, preservando-se os bens dos herdeiros. Entretanto, o Supremo Tribunal Federal, ainda à luz do Código Civil revogado, decidiu que "uma vez providenciada a abertura do inventário, com os bens dados à partilha, não é de exigir-se seja ela julgada para ensejar que o casamento do viúvo se faça sob o regime da comunhão de bens" ${ }^{11}$. Acompanhando o precendente ( $R E n^{\circ} 76.229$ ), cujo Relator foi o Min. Djaci Falcão, o STF reiterou o entendimento de que, "dados todos os bens à partilha, deliberada esta pelo juiz e feito o respectivo esboço, sem haver, no prazo legal, qualquer impugnação dos interessados, em princípio, nenhum dever resta ao pai ou à mãe, que pretende contrair novo casamento"12.

A regra relativa à mulher viúva ou separada do marido por nulidade ou anulação do casamento, até dez meses depois da viuvez, busca evitar a chamada turbatio sanguinis (confusão de sangue), em decorrência da presunção de paternidade que se impõe ao marido, quanto aos filhos concebidos na constância da convivência conjugal (pater is est).

O tutor ou curador e certos parentes dos mesmos com a pessoa tutelada ou curatelada constitui regra de proteção ao incapaz, a fim de não se permitir que, antes de prestadas e aprovadas as contas, ocorra o casamento, para Clóvis Beviláqua, o legislador teve o intuito de " $1^{\circ}$, de evitar que o tutor ou curador procurasse, no casamento, ocultar a delapidação da fortuna

\footnotetext{
${ }^{11}$ SUPREMO TRIBUNAL FEDRAL, Primeira Turma, Relator Min. Rafael Mayer, Recurso Extraordinário $\mathrm{n}^{\circ}$ 89.711/MG, j. 04.03.1980. Disponível em: <http://www.stf.jus.br>. Acesso em: 31.10.2017.

${ }^{12}$ SUPREMO TRIBUNAL FEDRAL, Primeira Turma, Relator Min. Djaci Falcão, Recurso Extraordinário no 76.229/MG, j. 02.10.1975. Disponível em: <http://www.stf.jus.br>. Acesso em: 31.10.2017.
}

\section{Revista de Direito de Família e Sucessão | e-ISSN: 2526-0227 | Maranhão | v. 3 | n. 2 | p.}


cuja administração lhe fora confiada; $2^{\circ}$, de pôr um freio á sua cubiça; $3^{\circ}$, de prevenir coacção sobre o animo da pessôa em relação á qual tenha adquirido ascendencia por suas funcções" (BEVILÁQUA, 1933, p. 89). Semelhante objetivo justificou a regra referente aos órfãos (art. 258, parágrafo único, III, do Código Civil de 1916.

A regra relativa ao homem maior de 60 (sessenta) e à mulher maior de 50 (cinqüenta) anos, conforme Pontes de Miranda, teria sido instituída "para evitar explorações, consistentes em levar-se ao casamento, para fins de comunhão de bens, mulheres em idade vulnerável, ou homens em fase de crise afetiva" (PONTES DE MIRANDA, 2001, v. 2, p. 219).

Em todos os casos, supra indicados, a consequência patrimonial do casamento era a separação obrigatória. E, como se disse, apesar de o art. 259 do Código Civil de 1916 referirse ao silêncio do contrato - o que poderia restringir sua incidência às hipóteses de separação convencional - o STF editou a Súmula $n^{\circ} 377^{13}$, que estendeu o princípio da comunicação dos aquestos ao regime de separação obrigatória de bens.

Com isso, por meio da súmula $n^{\circ} 377$, o STF estendeu a presunção de comunicabilidade contida no art. 259, CC/1916, ao regime da separação obrigatória (art. 258, parágrafo único, do mesmo Código), como se verifica em diversos acórdãos ${ }^{14}$.

Com a edição da súmula $\mathrm{n}^{\circ}$ 377, conquanto tenha sido uniformizado, no STF, o entendimento de que "no regime de separação legal de bens, comunicam-se os adquiridos na

\footnotetext{
${ }^{13}$ STF, Súmula $n^{\circ}$ 377. No regime de separação legal de bens, comunicam-se os adquiridos na constância do casamento.

${ }^{14}$ CASAMENTO. REGIME DE BENS. SEPARAÇÃO LEGAL. Os bens havidos, na constância do casamento, por um dos cônjuges, em virtude de herança, não se comunicam. A súmula 377 refere-se à comunicação de aquestos, no regime de separação legal. Não é invocável, quando se cuida de bens adquiridos, na constância do matrimônio, não pela cooperação de ambos os cônjuges, mas por herança. Código Civil, arts. 259 e 258, parágrafo único, inciso I. Sendo de separação legal o regime de bens, no desquite litigioso, não é de assegurar meação, quanto aos bens havidos por herança, na constância do casamento. Negativa de vigência do art. 259, do CCB, que não se verifica. Recurso extraordinário não conhecido. (SUPREMO TRIBUNAL FEDERAL, Primeira Turma, Relator Min. Néri da Silveira, Recurso Extraordinário n 93.168, j. 18.10.1984. Disponível em <http://www.stf.jus.br>. Acesso em 31.10.2017).

CIVIL. REGIME DE BENS NO CASAMENTO. No regime da separação legal de bens, não se comunicam os adquiridos com o produto da venda de bens anteriores ao casamento. Inaplicabilidade da súmula 377. (SUPREMO TRIBUNAL FEDERAL. Segunda Turma, Relator Min. Leitão de Abreu, Recurso Extraordinário nº 93.153, j. 02.10.1981. Disponível em <http://www.stf.jus.br>. Acesso em 31.10.2017).

Comunhão de aquestos no regime de separação legal de bens (súmula 377). Exclusão, todavia dos bens reservados (arts. 246 e 263, XII do Código Civil, na redação da Lei n 4.121/1962). Dissídio jurisprudencial inexistente. Recurso extraordinário não conhecido. (SUPREMO TRIBUNAL FEDERAL, Segunda Turma, Relator Min. Xavier de Albuquerque, Recurso Extraordinário n 85.315, j. 20/08.1976. Disponível em <http://www.stf.jus.br>. Acesso em 31.10.2017).
} 
constância do casamento", sem perquirir se cada cônjuge havia ou não colaborado para a formação dos aquestos, tal demonstração passou a ser exigida em alguns acórdãos do STJ, instaurando-se, nesse Superior Tribunal, uma divergência que ainda perdura.

Em outras palavras, na jurisprudência do STF não há necessidade de comprovação do esforço comum para na aplicação da súmula $n^{0} 377^{15}$. No STJ, porém, há posições dissonantes. Para a Quarta Turma, são partilháveis os aquestos, desde que adquiridos pelo esforço comum, nos termos da súmula $\mathrm{n}^{\circ} 377$ do $\mathrm{STF}^{16}$. Para a Terceira Turma, o esforço comum é presumido ${ }^{17}$. Parece mais coerente a posição adotada pela Terceira Turma do STJ, ao entender dispensável a prova do esforço comum, tendo em visto ter sido essa a posição primitivamente acolhida pelo STF, além do fato de a súmula não fazer qualquer referência a tal aspecto, mas, principalmente, porque a presunção de esforço comum se deriva da comunhão plena de vida, tanto assim que a separação de fato conduz à incomunicabilidade de bens.

Não obstante, verifica-se que a Segunda Seção do STJ, em 2015, unificou o entendimento quanto à questão, exigindo a prova do esforço comum para a partilha dos aquestos no regime da separação obrigatória:

EMBARGOS DE DIVERGÊNCIA NO RECURSO ESPECIAL. DIREITO DE FAMÍLIA. UNIÃO ESTÁVEL. COMPANHEIRO SEXAGENÁRIO. SEPARAÇÃO OBRIGATÓRIA DE BENS (CC/1916, ART. 258, II; CC/2002, ART. 1.641, II). DISSOLUÇÃO. BENS ADQUIRIDOS ONEROSAMENTE. PARTILHA. NECESSIDADE DE PROVA DO ESFORÇO COMUM. PRESSUPOSTO DA PRETENSÃO. EMBARGOS DE DIVERGÊNCIA PROVIDOS.

1. Nos moldes do art. 258, II, do Código Civil de 1916, vigente à época dos fatos (matéria atualmente regida pelo art. 1.641, II, do Código Civil de 2002), à união estável de sexagenário, se homem, ou cinquentenária, se mulher, impõe-se o regime da separação obrigatória de bens.

\footnotetext{
${ }^{15}$ SUPREMO TRIBUNAL FEDERAL: Primeira Turma, Relator Min. Néri da Silveira, Recurso Extraordinário $\mathrm{n}^{\circ}$ 93.168, j. 18.10.1984; Segunda Turma, Relator Min. Xavier de Albuquerque, Recurso Extraordinário ${ }^{\circ}$ 85.315, j. 20/08.1976.

${ }^{16}$ SUPERIOR TRIBUNAL DE JUSTIÇA: Quarta Turma, Relator Min. Luis Felipe Salomão, Recurso Especial n. 646259/RS, j. 22/06/2010; Relator Min. Aldir Passarinho Junior, Recurso Especial n. 123633/SP, j. 17/03/2009; Relator Min. Sálvio de Figueiredo Teixeira, Recurso Especial n. 9938-0/SP, j. 09/06/1992.

${ }^{17}$ SUPERIOR TRIBUNAL DE JUSTIÇA: Terceira Turma, Relator Min. Vasco Della Giustina (Des. convocado do TJ/RS), Recurso Especial n. 1199790/MG, j. 14/12/2010; Relatora Min. Nancy Andrighi, Recurso Especial n. 1171820/PR, j. 07/12/2010; Relator Min. Carlos Alberto Menezes Direito, Recurso Especial n. 736627/PR, j. 11/04/2006).
}

\section{Revista de Direito de Família e Sucessão | e-ISSN: 2526-0227 | Maranhão | v. 3 | n. 2 | p.}


2. Nessa hipótese, apenas os bens adquiridos onerosamente na constância da união estável, e desde que comprovado o esforço comum na sua aquisição, devem ser objeto de partilha.

3. Embargos de divergência conhecidos e providos para negar seguimento ao recurso especial ${ }^{18}$.

Cumpre ressaltar que a súmula $\mathrm{n}^{0}$ 377, do STF, foi aprovada em sessão plenária de 03.04.1964, antes, portanto, da Lei do Divórcio (Lei n. 6.515/1977), que modificou o regime supletivo legal (antes comunhão universal e, daí em diante, comunhão parcial).

Ou seja, a súmula surgiu em uma época em que a regra geral era a comunhão universal, o casamento era indissolúvel e vigia o art. 259, do Código Civil de 1916, como instrumento de interpretação dos pactos antenupciais (in dubio pro communionem). Portanto, os recursos que culminaram na súmula $\mathrm{n}^{0} 377$ versavam sobre a interpretação do art. 259, do Código Civil de 1916.

A discussão referia-se à possibilidade ou não de ser aplicado o dispositivo que aludia ao silêncio do contrato às hipóteses de separação obrigatória. Prevaleceu a tese de que os casados pela separação obrigatória não estavam proibidos de celebrar pacto antenupcial para excluir os frutos dos bens e, se o fizessem, no silêncio do contrato, os demais aquestos se comunicariam. Além disso, o STF vinha decidindo que italianos, separados no país de origem, mas vivendo no Brasil, tinham direito à partilha dos aquestos aqui adquiridos pelo esforço comum (presumido) ${ }^{19}$. Portanto, a súmula $n^{0} 377$ do STF nasceu da interpretação do art. 259, do Código Civil de 1916.

Não há norma equivalente ao art. 259, do Código Civil de 1916, no Código Civil de 2002. Logo, por força do disposto no art. 2.039, do Código vigente, não haveria como aplicar o art. 259 e tampouco a súmula no 377 aos casados sob a vigência do Código de 2002.

Todavia, contrariando tal lógica, fundada na proteção ao direito adquirido (art. 2.039), o STJ continua aplicando, concessa venia, contra legem, a súmula $\mathrm{n}^{0} 377$ do STF, chegando a exigir outorga conjugal para os casados sob a separação obrigatória, pela incidência da mencionada súmula ${ }^{20}$.

${ }^{18}$ EREsp 1171820/PR, Rel. Ministro RAUL ARAÚJO, SEGUNDA SEÇÃO, julgado em 26/08/2015, DJe 21/09/2015.

19 SUPREMO TRIBUNAL FEDERAL. Tribunal Pleno, Relator Min. Hahnemann Guimarães, Recurso Extraordinário n. 8984, j. 08.11.1948.

${ }^{20}$ SUPERIOR TRIBUNAL DE JUSTIÇA. Terceira Turma, Rel. Min. Vasco Della Giustina (Des. convocado do TJ/RS), Recurso Especial n. 1199790/MG, j. 14/12/2010. 
Cuida-se de verdadeira inovação que, segundo Larenz, constitui uma "ruptura éticojurídica" ${ }^{21}$ em relação a todos os precedentes anteriores, pois o tribunal não poderia atribuir uma nova eficácia (necessidade de outorga conjugal) ao regime, que consta no registro público como separação obrigatória, com alcance inter partes e erga omnes, sem uma gravíssima quebra da confiança e das legítimas expectativas de todos os envolvidos (LARENZ, 1997, p. 618).

\section{CONCLUSÃO}

O direito patrimonial do casamento, previsto no Código Civil de 2002 (Livro IV, Título II), embora formulado para o século XXI, guarda grande semelhança com o sistema anterior, exceto quanto à substituição do regime dotal pelo regime de participação final nos aquestos e quanto às necessárias adaptações, constitucionalmente impostas, que se refletiram no chamado regime primário ou estatuto imperativo de base, que contém regras gerais, de ordem pública, referentes a certos efeitos pessoais e patrimoniais do casamento, cuidando o legislador em somente um dispositivo do direito intertemporal.

Afora isso, os problemas advindos da sucessão de leis não recebe abordagem nos clássicos (ou, quando há, trata-se de simples menções superficiais), tampouco figurando nas obras mais recentes de direito de família (LARENZ, 1997, p. 618).

Com efeito, o confronto da única disposição transitória presente no direito de família (art. 2.039 do Código Civil) com a teoria geral e a jurisprudência permite revelar uma verdadeira assistematicidade na política seguida pelo legislador na seara do direito de família, que sofreu e sofre tantas mudanças.

A despeito de o legislador ter disciplinado detalhadamente as regras patrimoniais do casamento, dúvidas frequentemente surgem, quando da partilha de bens, devido à complexidade das relações econômicas entre os cônjuges e com terceiros.

O direito vigente no momento da celebração do casamento, em princípio, regerá, no futuro, algumas relações patrimoniais entre os cônjuges, afastando-se a incidência de leis supervenientes de direito material, a fim de serem preservados o direito adquirido e o ato jurídico perfeito. 
Essa irretroatividade, prevista nas disposições finais e transitórias do Código Civil vigente, no art. 2.039, deveria aplicar-se aos regimes de bens, inclusive no tocante à súmula $\mathrm{n}^{\circ} 377$ do STF.

Portanto, pode-se concluir que a jurisprudência não adota critérios para aplicação do direito intertemporal no direito de família, sendo o maior exemplo a questão da súmula $\mathrm{n}^{\circ} 377$ do STF, matéria sobre a qual há divergências e ausência de coerência, consoante as normas do direito transitório.

Demonstrou-se, ainda, no presente artigo, sob o marco teórico de Paul Roubier e metodologia dedutiva, que não haveria como aplicar a súmula $n^{\circ} 377$ aos casados sob a vigência do Código de 2002, como, concessa venia, erroneamente vem decidindo os tribunais superiores.

\section{REFERÊNCIAS}

BATALHA, Wilson de Souza Campos. Direito Intertemporal. Rio de Janeiro: Forense, 1980.

BEVILÁQUA, Clóvis. Direito da Família. Rio de Janeiro: Freitas Bastos, 1933.

CARDOZO, José Eduardo Martins. Da retroatividade da lei. São Paulo: RT, 1995.

DELGADO, Mário Luiz. Problemas de Direito Intertemporal no Código Civil: doutrina e jurisprudência. São Paulo: Saraiva, 2004.

DINIZ, Maria Helena. Lei de Introdução ao Código Civil Brasileiro Interpretada. 11. ed., São Paulo: Saraiva, 2005.

DIREITO, Carlos Alberto Menezes. Da união estável no novo Código Civil. Família e Jurisdição. BASTOS, Eliene Ferreira e SOUSA, Asiel Henrique de (Coords.), Belo Horizonte: Del Rey, 2006

ESPÍNOLA, Eduardo, ESPÍNOLA FILHO, Eduardo. A Lei de Introdução ao Código Civil Brasileiro. (atual. Silva Pacheco). 3. ed., Rio de Janeiro: Renovar, 1999, v. 1. 
FERRAZ JÚNIOR, Tércio Sampaio. Introdução ao Estudo do Direito: técnica, decisão, dominação. 2 ed., São Paulo: Editora Atlas, 1994.

FRANÇA, Rubens Limongi. A irretroatividade das leis e o direito adquirido. 3. ed., São Paulo: RT, 1982.

MAXIMILIANO, Carlos. Direito Intertemporal. 2 ed. Rio de Janeiro: Freitas Bastos, 1955.

OLIVEIRA, J. M. Leoni Lopes de. Introdução ao Direito Civil. Rio de Janeiro: Lumen Júris, 1998, v. 1.

LARENZ, Karl. Metodologia da ciência do direito. (trad. José lamego). $3^{\mathrm{a}}$ ed., Lisboa: Fundação Calouste Gulbenkian, 1997.

MAFRA, Tereza Cristina Monteiro et alii. A LICC e o Código Civil de 2002. Rio de Janeiro: Forense, 2008.

MALAURIE, Philippe. Les contrats contraires à l'ordre public. Étude de droit comparé: France, Anglaterre, U.R.S.S. Paris: Matot-Braine, 1951.

MAXIMILIANO, Carlos. Direito Intertemporal ou Teoria da Retroatividade das Leis. 2 ed., Rio de Janeiro: Freitas Bastos, 1955.

NIBOYET, 2008; La contractualisation da la famille. (Sous la direction de Dominique Fenouillet et Pascal de Vareilles-Sommières). Paris: Economica, 2001.

OST, François. O tempo do direito. (trad. Élcio Fernandes). Bauru, SP: Edusc, 2005.

PIRES, Maria Coeli Simões. Direito adquirido e ordem pública: segurança jurídica e transformação democrática. Belo Horizonte: Del Rey, 2005.

PONTES DE MIRANDA, Francisco Cavalcanti. Tratado de Direito de Família. São Paulo: Bookseller, 2001, v. 2.

ROUBIER, Paul. Le droit transitoire: conflits des lois dans le temps. Paris: Dalloz, 2008.

Paul. Les conflits de lois dans le temps: theorie dite de la non-retroactivité des lois. t. 1, Paris: Recueil Sirey, 1929. 